\title{
A Reflection of American Spirit: The Analysis of Cowboy Images in American Movie True Grit
}

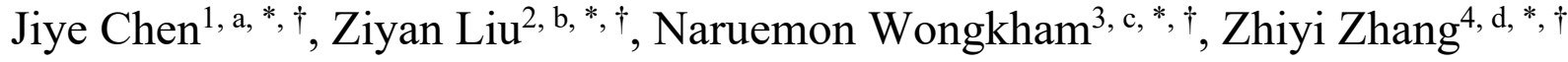 \\ ${ }^{1}$ Nanchang Business School, Jiangxi Agricultural University, Nanchang, 330044 China \\ ${ }^{2}$ Beijing Royal School, Beijing, 102200 China \\ ${ }^{3}$ Classical Dance Department, Beijing Dance Academy, Beijing, 100039 China \\ ${ }^{4}$ Jiangsu Tianyi High School, Wuxi, 214000 China \\ *Corresponding author.Email: ${ }^{*} 1014689587 @ q q . c o m,{ }^{b}$ liuziyanbx@126.com, ${ }^{c}$ guanghua.ren@gecacademy.cn, \\ diamandreaz@163.com \\ These authors contributed equally.
}

\begin{abstract}
It is believed that western cowboy images are full of wilderness, fiery hearts, rye whiskey, and leather gloves. Besides these features, there are more valuable perspectives to explore. Since female status in western movies at that time was not obscure and lack of respectable reviews. The movie True Grit is worth viewing for its Oscar Award and immersive illustration of a female character. In this research paper, with the quantitative methodology, it is found that cowboy spirits have been deeply influenced by American history and cultural background and have consistently been expressed in traditional western movies to give the characters the values such as courage, fearlessness, and independence. These values, which are believed to reflect the whole American spirit and historical style without gender identification, are thoroughly represented in the movie True Grit as a classic model in the overall American movie industry to help the audience achieve a further understanding of the true cowboy spirit and its relationship with the general American culture.
\end{abstract}

Keywords: Cowboy, Cowboy spirit, Western movie, American culture.

\section{INTRODUCTION}

Cowboy images today are popular among the world, especially in the expression of fashion styles such as a bandana, jeans, cowboy boots, or long hair. They had a long history in America, originated from "Vaquero" in Northern Mexico in about the 19th century. They used to work on the ranch with houses and then spread to other western parts of the world, even far south to Argentina. It has been long believed that American cowboys were pioneers who explored harsh environments to live in and mastered an elaborated skill of using guns to protect American residents from the attack of native Americans or Mexican bandits. These kinds of cruel and insecure living conditions gave them a particular spirit of cowboys. They are reliable and generous to share the findings and explore the outer world; they are heroic and intrepid to face all difficulties and keep danger away [1]. Though, under such circumstances, they are free to release all rude passion, which makes them open fire without any hesitation even to a compatriot. Since the inner quality of cowboys is still complex, to look closer to the cowboy images, western movies are one of the best ways to analyze, which cowboy representatives have long relied on.

Western films are a type of film that specifically occurs in the western region of the United States, especially in Texas. The film's kind of story generally takes place in a small society without formal judicial organizations. Additionally, violence is a common means of solving problems. On the other hand, precisely because there is no judicial organization, justice cannot be carried out rationally like in urban society, and in this space, the cowboy was born. They often came and went without a trace. Their marksmanship is like a god. Meanwhile, they love justice, and they bury violence in peace. In this sense, actually, "cowboy" is a sense of warrior culture in some dimensions. Cause they occurred in the legend of the law cannot be reached. The first western movie was released in 1903 in America, named The Great Train Robbery, directed by Edwin Stanton Porter. This silent film just only about 10 
minutes, but it drives the development of cowboy movies [2]. In recent years, the most popular cowboy films were Brokeback Mountain, adapted from Annie Proulx's novel, and won 38 awards. Django Unchained by Eric Marlon Bishop, Christoph Waltz, won the 70th Golden Globe Awards, the 66th British Academy Film Awards, and the 85th Academy Awards and got good audiences' reviews.

As for many people in our time who hold an opinion about Western cowboy culture representing flashy and dandified style, True Grit is a game changer. This film is epic. Focusing on the main character's revenge, it vividly portraits the American Western cowboy/cowgirl image in the time of the 1870s, while Western and Southern America are in turbulence after the Civil War. It was also the first time that a very distinctive cowgirl appeared on the screen, who had many of the characteristics of a traditional cowboy -- loyalty, bravery, and navigating the conflict between justice and brutality. True Grit made its debut in 1969. After decades, in 2011, it was again adapted and got onto the stage. The film was a huge hit at that time and had won Oscars for Academy Award for Best Picture, Best Adapted Screenplay, Best cinematography, and so on.

The story begins in the Southern US in the 1870s. At that time, the American Civil War had just ended, and bandits were rife in the unpoliced American West. The main character, Ross, has just lost her father in such a time of turmoil. In addition to retrieving her father's body, Ross is determined to track down the murderer, namely the hired hand Tom Chaney, to avenge his father's death. Encountering all the difficulties of finding Sheriff Cogburn, Ross meets LeBeouf, who is also looking for Chaney. After some twists and turns, the three decided to hit the road together. The adventure of the three is full of breathtaking danger. Eventually, Ross avenges her father by killing Chaney but is also bitten by a venomous snake while she falls down the cave. Cogburn rode to Bear man's house all night to save Ross, and finally, Ross was saved. Fast forward 25 years, Ross can't forget Cogburn's saving her life. She comes to the area and sadly hears the news of Cogburn's death and decides to bury him in her home.

\subsection{Literature Review}

Because of the different portraits of a cowboy in all kinds of artworks or folktales in this rather long-time span, people's perception of what a real cowboy is has been shaped and reshaped while time flows forward. In the late 19th century, stories of cowboy legend, like how cowboys in Panhandle had a field day with Archibald John Marjoribanks, the British baron and owner of Rocking Chair branch (a gentleman, graceful and polite), they shot at his feet and made jokes about him. This kind of harmless and had led the public to view cowboys as they are "holding the line against the effeminate dudes from out East who dared to invade their territory" [3]. Also, from Boule de Suif and True Grit, we get a sense of ambivalence in cowboy characteristics. Standing amid the chaos, they are tough but struggled, struggled between justice and violence, between the pursuit of inner freedom and restraint given by the chaotic world. Their violent crimes of punishing evil and promoting good are heroic, and they are seen as the embodiment of justice and a symbol of bravery.

However, we can see a clear transition of perception of the cowboy as a representative figure from the artworks of 1970-the 1980s. In the late 1970s and early 80 s, cowboys emerged as an entertainment destination not confined to western or rural America, nor concerned with heroism, past cowboy incarnations. Watching the film Urban Cowboy, there is a scene in which the character Sissy introduces herself to Bud at a bar. She opens with a question: "Are you a real cowboy?" According to Carpenter, he was struck by the contradictory treatment of the cowboy in this and other moments of the film. He comments: In the face of a desire for an unequivocal declaration of cowboy authenticity — "a real cowboy"- the film evades commitment, offering only that the cowboy's realness pertains more to the asker than the asked. As for that time, the ambivalence of the cowboy tends to make a mark in other ways: Make a mark in other ways. They contradict sexual fidelity/promiscuity, greed/altruism, and forgiveness/revenge [4].

One of the western movies about cowboys, Brokeback Mountain, is a good example of cowboy trend and spirit, which is worth reviewing. This movie describes two traditional cowboy characters who fall into an unusual relationship, that is, homosexual love. At that time, people had a stereotype of cowboys who had personalities of tough and rough and showed enough masculinity. So, the emergence of Brokeback Mountain is undoubtedly shocking for the audience, even to the actors. According to Oliver Lyttelton, the public has raised up a strong dispute about the sexuality and love between two male cowboys [5]. Many famous male movie stars were unwilling to be the main role because they were obviously astonished by the creative visualization shown in the movie. This movie also received lots of resistance from the American Catholic Church that it was a moral ravage on the heterosexuality that people should abandon. Despite the criticisms, the success of this movie is prominent. Raising the public's attention in various areas powerfully showed the cowboy's rebellion toward the traditional stereotype as an American cowboy spirit. As an extensive LGBT group, Donald Collins further made remarks on the sexual aspect of Brokeback Mountain. In his article That "Gay cowboy movie", there are quotes from the writer and filmmaker, indicating that this movie has a great effect on stating the relationship between homosexuals [6]. It gives cowboys a strong personality but more 
genuine, which breaks the inherent and monotonous representatives of cowboys, giving them more diverse characteristics and inner qualities in a tolerant perspective.

According to From Blood Simple to True Grit: A Conversation about the Coen Brothers' Cinematic West, Joel Coen, and Ethan Coen is the most famous movie directors, scriptwriter film production of America. The two often collaborate to complete works, so they are called Coen Brothers. From crime to suspense absurd comedy, to literary biography, the Coen brother's movie types, distinctive style, full of strong feelings and discussion of humanism philosophy of death [7].

However, the creative power of the Coen brothers is declining, and they are also aware of this. After Inside Llewyn Davis, they took a two-year break to help Angelina Jolie and Spielberg polish the scripts of Unbroken and Bridge of Spy, but it is difficult to see the author's label on them. It is also mentioned that Printing the Legend Classic Western Influence on The Shootist, Unforgiven, True Grit and Zombieland. Today, a similar image has been injected the new meaning, as amended US Westerns help expand the types of boundaries, so creators and critics explore the moral image of life in border-related non-traditional Western's narrative like In Ang Lee's "Brokeback Mountain and Coen brothers' Ture Grit [8]. According to Roger Ebert, Mattie Ross embodied typical American spirits of strong will, determination, and intelligence in her employing Cogburn to avenge the murder, Tom Chaney [9]. She presents herself as able as a man and saves women from the status of undervaluation to a great extent. Also, Philip French focused on cowboys in the west represented by Rooster Cogburn and Ranger LaBoeuf. Its elaborated descriptions about the characters' diverse personalities reflect the realism and the critics from the cruel society and give cowboys a much more vivid image that shows their richness inside [10].

There are plenty of western movies in the last 100 years since the first western. The Great Train Robbery and massive references are available. However, there are limited literature reviews and researchers on the internet to delve into the brand-new cowboy image and penetrate the cowboy image of witty, brave, composed, and calm men who can deal with unexpected accidents on the way and danger with American spirit. According to the situation mentioned above, this research can fill in the gap by giving the audience a more comprehensive view of the American cowboy spirit through the movie True Grit. The significance of this study is that, through the research from a social media with a high reputation as well as the analysis from the writers _ young generations who live separately from the cowboy life in the past and possess an objective perspective towards this cultural spirit — the lack of remarks on True Grit about the cowboy image and spirit behind can be extended to an upper level. Moreover, this research works as a guide that leads American film industries or even other international ones to better illustrate cowboy trends and better express the meaningful spirit behind their following western movie process.

This paper uses qualitative research method, take the film True Grit that has won an American Academy Award (Oscars) as an example, analyze the image of American cowboys and cowgirls in this movie Rooster Cogburn and Mattie Ross. In addition, explore the American spirit behind it.

\section{RESULTS \& DISCUSSION}

\subsection{The Spirit Of Punishing The Evil And Praising The Good}

According to our findings, there are mostly four qualities in True Grit: the spirit of punishing the evil and praising the good, courage and resolute, independence, and fearlessness, to be analysed.

The movie True Grit is a typical one of "revenge" as the theme: the courage to promote the spirit of American Westerns. The story begins in the 1870s in the southern United States. Shortly after the Civil War, the legal system is not fully developed, and many areas have become rampant robber Lawless. Because his father was brutally killed by the robber Cheney, the 14year-old daughter Rose decided to hire the local oneeyed bailiff Coburn to chase the fugitive Cheney and personally bring Cheney to justice. Then Texas Mounted Police Leboeuf found Ross, requires accompanying Cheney alive, after three run-trust, to capture the same enemy and fight side-by-side. In the vast wilderness perilous, they join forces shot dead bandit, Ross finally hands Revenge for the father, ended the journey of revenge.

Although Marty is only fourteen years old, she is by no means naive. Whether it is for the law or emotion, everyone is nothing more than an animal of interest. In the beginning, when the pastor of the funeral home filled her with spirit soup, she didn't take the call and only cared about why the price was different from the previously stated money. Even to sue to sell a horse merchant of the time, he highlighted their cards, our family a widow with three children, as long as one crying in court, you're done. Facing this savage and rampant wild continent, the adults used guns in their pockets to reason, and Marty, the mediocre-looking little girl, had the only weapon of law and morality. Contrast that with the old version of the story of the film violence with violence, the child weak to defeat the evil with the power of civilization, chaos attributed kernel order, apparently fuller of depth. The fierce contrast between the weakness of the external force and the strength and tenacity of Marty's heart is very dramatic in 
itself, and the adults of various identities and personalities along the way are like different mirrors, reflecting her different appearances, guarding the company. Teach her to experience this great adventure and to complete a transformation like a coming-of-age ceremony together.

True Grit also reflects the image of American cowboys who are courageous and resolute. When Mattie Ross, only a fourteen-year-old girl, desired revenge for her father, she desperately rode a foal across the wide river, water almost submerged little horse and herself, but she has no fear in her eyes, she holds onto the bridle and swims ashore. In addition, when one-eyed marshal Rooster Cogbum fight against four enemies, he seems like the king of this land, not afraid of everything. He was armed with two revolvers, shooting at the enemies. These relevant plots demonstrate cowboys' or cowgirls' charm, in terms of these features precisely represent a part of the American spirit. Back in the eighteenth century, cowboys were merely proletariat. Most of them were employed by livestock merchants. Cowboys' job was to graze long distances. They must be able to cope with all kinds of unpredicted and unsafety accidents, not only with the herd but also need to control the half-tame cattle. Along the way, it should also pay much more attention to the wolf pack and other beasts or poisonous snakes, poisonous insects attack, to guard against the Indian's javelins [11]. That is why True Grit shows the bravery and decisiveness side of Mattie Ross and Rooster Cogbum.

Besides what has been mentioned in the previous paragraphs, independence is expressed vividly in this movie, which soaks in the fourteen-year-old female character's personality and makes her succeed at last. We can see that, at the beginning of the movie, when the girl was told to carry her dead father home, she made decisions along with no matter that her mother told her to go home or she was in a poor and hard time because she had no money or a good place to rest. She was a girl that was quite different from others of the same age and those who were in the mind of other adults. She could deal with things on her own no matter how troublesome they were. Literally, it is shocking to see that Rose-a young girl who has just lost her father and has to take the great responsibility as a family memberpossesses an elaborated skill of negotiation to use her unique mind and excellent eloquence to persuade others and try to reach her goal in a win-win method without losing demeanour and dignity, giving the role with the scene of asking for initial capital when taking to the cotton trader as well as the opportunity to convince Marshal Rooster Cogburn. Mostly, her quick thinking and a silken tongue arise from her precious value of being independent. All the way, the only person she can rely on is herself.
Despite these obvious expressions of this valuable personality, actually, there is one thing that we should dig deeper into. Someone may argue that, though Rose is a tough girl who decides to revenge for her father along, the help from Cogburn and Laboeuf is the key point of the girls' success. Without these two people, Rose could not have any clues for chasing the enemy, facing physical danger, or being saved from the snake cave. These are all true. However, independence does not represent being alone or complete tasks individually. A person's independence is to have independent thoughts and independent beliefs while being under others' care and reliance. The character is independent because she did not give up everything she wanted just because she was intimidated. It is also because of her independence. She can be followed by two hero's trust and help, triumphantly escape from danger, and be saved through others' sacrifice.

So, independence is a quality that makes a person rely on himself and a strong weapon to inform others that he has his own thinking and capability to follow his belief, which wins the person others' respect and faith as a reward. And this quality has long been found in the whole American spirit, no matter on a cowboy or a common resident. It is known that the United States has long been the homeland of American Indians who British people invade through their world exploration. Later, the great American Revolution War happens from 1775 to 1783, separating American people from British ones and making the country's citizens become a newly formed group called the "united states" apart from any other country in the world. After that, America has experienced many others wars, such as the American Civil War, which also incarnates the American spirit of independence that they do not rely on others but still build bridges with other countries through transportation, trade economy, and other international collaborations. Independence is the value that Americans spend their lifetime purchasing, which is successfully embodied in the movie True Grit on its main female character.

Bravery is also one of the most apparent features a cowboy could have. According to Allen, Cowboys were bound by the Code to be brave and steadfast in the line of duty [12].

This code contained many features that resemble the unique characteristics ascribed to American frontiersmen by historian Frederick Jackson Turner in his seminal 1893 essay "The Significance of the Frontier in American History. Yet True Grit has brought it up to a higher level. Having a sleepover with dead bodies needs gut; shooting and killing people without shaking hands requires sufficient calm and decisiveness. These are all the brave things done by Ross, and hereby calling her brave means she has no fear, and she is courageous. But Ross goes further. From here, we can see that courage is not just about being willing to challenge 
others or the conventional frightening things. True courage is heroic. It requires people to face their inner fears and constantly refresh their psychological defenses. For the latter, cowards are always yesterday's self. Losing her father, there is not much time for Ross to grieve. Said Ross, "I'm about to embark on a great adventure... ... Though I walk through the valley of the shadow of death, I shall fear no evil (from Bible Psalm 23:4). The author of all things watches over me, and I have a fine horse." Right here, we can actually see the influence of religious beliefs on the cowboy image in this movie. It can be said that the power of the Creator gave them some courage.

\subsubsection{Courage And Resolute Of The American Cowboys}

After analyzing the personalities and American spirit in this movie, people might want to know the influence of True Grit on the audience since the viewers' reflections are one of the important standards that judge the movie's quality. As said by R. Kaulingfreks et al., what is key here is that cowboys take the risk. And once they accept that risk and make a decision, they never look back but pursue their goal with a tenacity bordering on single-mindedness [13]. From the background of the original story to all elements of the film in True Grit, cowboys are the backbone. The audiences' various evaluations of True Grit are also mainly about cowboys. Although few contemporary Americans have truly experienced cowboy life, the world has equated cowboys with the United States, the cowboy's spirit, which has been considered part of American culture and integrated with the national spirit since the last century. Cowboys are majestic, arrogant, fearless, and fight against injustices. These images can not only be found in politics and various signs.

At the end of the film, Mattie put on a black dress, stood in the cemetery, and then resolutely left, saying this during the period, there is no doubt that there is a lot of gossips, they said, "She doesn't even know that person", "She is a delirious old maiden." This passage is like the end of "The Old Man and the Sea". Santiago drags his bones back to the coast. No one knows the story behind it. And Mattie doesn't care about it, just like San Diego doesn't care about everyone. Seeing Mattie's fading back, the story ends like this, in line with the last sentence in the film: Time always slips away from us quietly. By following the film True Grit, people can deeply interpret the realistic cowboy's image of courage and resolute, not only can show on the cowboys but also can be reflected in cowgirls, with the aim of can push both the American culture as well as western cowboy culture, that people interested to know what is behind bolstered cowboys' culture.

It is believed that True Grit is successful not only because of its mastered description of the whole story and different characters but also because it resonates with the audience. Punishing evil and promoting good, boldness, independence, fearless, these values are laudable. Especially when a "weak" girl in her teenage time has all these pleasing qualities, these spirits are more commendable and realistic. The audience, we believe, resonate with the female character because they know how hateful the evil can be when he committed the crime but still did not realize his guilt; they know how hard it is for a young girl who took the responsibility to revenge for her father along; they also feel the humanity among western characters when the tow heroes saved Rose without hesitation. The complexity of the event and the characters' inner parts are so exquisite that the audience will easily replace the movie characters with themselves to view things from the characters' standpoint. The movie wants to convey that the real world is full of cruelness and tragedies. With faith, courage, insistence, and independence, people can still reach their goal no matter how far it is.

One of the magical features of this film is that it fully embodies the well-known and recognized characteristics of cowboy culture - individualism and heroism. For these common characteristics shared by almost all cowboys, Turner said:

to the frontier, the American intellect owes its striking characteristics. That coarseness and strength combined with acuteness and inquisitiveness; that practical, inventive turn of mind, quick to find expedients; that masterful grasp of material things, lacking in the artistic but powerful to effect great ends; that restless, nervous energy, that dominant individualism, working for good and for evil, and withal that buoyancy and exuberance which comes with freedom-these are traits of the frontier, or traits called out elsewhere because of the existence of the frontier [14].

According to R. Kaulingfreks et al., the cowboy's heroism comes from his/her outsiderliness. Their strength and fearlessness that come from living alone are the qualities that enable them to be the one that can participate in a shoot-out. Ross embarks on the journey for revenge; LaBoeuf goes after a wanted man for his own purpose; Sheriff Cogburn seems to be motivated by money, but Ross finally moves him for the greater good. From the movie's plot, we can see that although these people stumble into each other by mistake, with the same goal, and help each other during the journey, we can't see the consistency of goal forward as in collectivism. This makes Cogburn's eventual rescue of Ross even greater because this action can be attributed to two main reasons: Cogburn's loyalty and the deep emotional bond between the two distinct individuals.

But intriguingly, what truly makes this film significantly outstanding is that while depicting the message that all classic Westerns are trying to convey, it 
subverts the popular stereotype of the cowboy, which is embodied in the portrayal of a teenage girl cowboy. Instead of what one might expect of a 14-year-old girl -naive, innocent, delicate, waiting to be rescued (like the one in the picture The New Bandit King rescuing a girl from the rapids, the 1880s-90s) -- Ross was heroic, tenacious, hostile, and willing to avenge for her father. In contrast with the picture of The New Bandit King rescuing a girl from the rapids, she has most of the cowboy features, but because of the scarcity of cowgirls, Ross's appearance in the film is subversive.

\section{CONCLUSION}

In conclusion, we found the movie True Grit shows image of whether cowboys or cowgirls, who are heroic, daring, fearless, and independent. From protagonists' performances analyses, they reflected cowboy personalities through the different plots. Not only does it lead people to a better understanding of the characteristics of cowboys in this film, but it also deeply explores the American spirit associated with cowboys. Through the characters' adventure, we found that special kind of independence and individualism engraved in the cowboy/cowgirl's mind, which lead them to make decisions courageously and resolutely. Also, the film does a remarkable job of resonating with the audience, who would be impressed by the tenacity of the cowgirl character, which is subversive, and the detailed portrayal of the cowboy spirit.

\section{REFERENCES}

[1] J.J. Nimmo, The American cowboy, Legends of America, $1886 . \quad$ Retrieved from: https://www.legendsofamerica.com/weamericancowboy/

[2] H. Susan, K. Hou, J.N. Zhong, The key word in cinematography - Western film, Film Art, 2004, (2), 121-126.

[3] J.M. Moore, “Them's Fighting Words": Violence, Masculinity, and the Texas Cowboy in the Late Nineteenth Century, The Journal of the Gilded Age and Progressive Era,2014, 13(1), 28-55. DOI: https://doi.org/10.1017/s1537781413000479

[4] P.J. Carpenter, The Cowboy and His Shadow: Queering Masculinity in the Regan--Bush Era, Carpenter, Peter Joseph, 2013. Retrieved from: https://escholarship.org/uc/item/4dx1m574

[5] O. Lyttelton, "Brokeback Mountain" turns 10: a look back at the controversy surrounding the cowboysin-love classic, 2015. Retrieved from: https://www.yahoo.com/entertainment/brokebackmountain-turns-10-a-look-back-at-the172157747.html
[6] D. Collins, That "gay cowboy movie", Bitchmedia, $2020 . \quad$ Retrieved from: https://www.bitchmedia.org/article/queer-roundupfifteen-years-brokeback-mountain

[7] N. Campbell, S. Kollin, L.C. Mitchell, S. Tatum, From Blood Simple to True Grit: A Conversation about the Coen Brothers' Cinematic West, Western American Literature, 2013, 48(3), 312-340. Retrieved from: https://muse.jhu.edu/article/526108/summary

[8] C. Yogerst, Printing the Legend Classic Western Influence on "The Shootist", "Unforgiven", "True Grit" and "Zombieland", Regent University, 2011. Retrieved from: https://www.proquest.com/openview/71b572c636c 98f65ac5838131081716b/1?pqorigsite $=$ gscholar $\& \mathrm{cbl}=18750$

[9] R. Ebert, You'd want Mattie Ross guarding your back, Rogerebert.com , 2010. Retrieved from: https://www.rogerebert.com/reviews/true-grit-2010

[10] P. French, True Grit-review, The Guardian, 2011. Retrieved from: https://www.theguardian.com/film/2011/feb/13/tru e-grit-coen-brothers-review

[11] D. Igler, Industrial Cowboys: Corporate Ranching in Late Nineteenth-Century California, Agricultural History, 1995, 69(2), 201-215.

[12] M. Allen, "I Just Want to Be a Cosmic Cowboy": Hippies, Cowboy Code, and the Culture of a Counterculture, The Western Historical Quarterly, 2005, 36(3), $275 . \quad$ DOI: https://doi.org/10.2307/25443192

[13] R. Kaulingfreks, G. Lightfoot, H. Letiche, The man in the black hat, Culture and Organization, 2009, 15(2), 151-165. DOI: https://doi.org/10.1080/14759550902925328

[14] F.J. Turner, J.M. Faragher, Rereading Frederick Jackson Turner: The Significance of the Frontier in American History and Other Essays (Henry Holt Reference Book) (1st ed.), Henry Holt \& Co, 1994. 